\title{
Pathogenic Parameters Derived from Activated Platelets in Dengue Patients
}

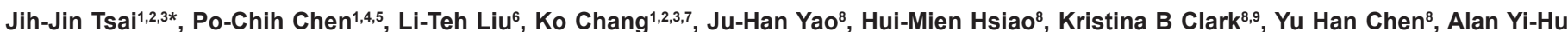
$\mathrm{Hsu}^{9}$ and Guey Chuen Perng ${ }^{8,9,10 *}$

${ }^{1}$ Tropical Medicine Center, Kaohsiung Medical University Hospital, Kaohsiung, Taiwan

${ }^{2}$ Division of Infectious Diseases, Department of Internal Medicine, Kaohsiung Medical University Hospital, Kaohsiung, Taiwan

${ }^{3}$ Department of Internal Medicine, School of Medicine, College of Medicine, Kaohsiung Medical University, Kaohsiung, Taiwan

${ }^{4}$ Department of Medical Laboratory Science and Biotechnology, College of Health Sciences, Kaohsiung Medical University, Kaohsiung, Taiwan

${ }^{5}$ Department of Laboratory Medicine, Kaohsiung Medical University Hospital, Taiwan

${ }^{6}$ Department of Medical Laboratory Science and Biotechnology, College of Medicine and Life Science, Chung-Hwa University of Medical Technology, Taiwan

${ }^{7}$ Department of Internal Medicine, Kaohsiung Municipal Hsaio-Kang Hospital, Kaohsiung, Taiwan

${ }^{8}$ Department of Pathology and Laboratory Medicine, Emory Vaccine Center, Emory University School of Medicine, Atlanta, GA

${ }^{9}$ Department of Microbiology and Immunology, National Cheng Kung University, Medical College, Tainan, Taiwan

${ }^{10}$ Center of Infectious Diseases and Signaling Research, National Cheng Kung University, Medical College, Tainan, Taiwan

\section{Abstract}

Platelets have been recognized to be an integral part of human immune system. Hematologic disfunction, such as thrombocytopenia, is one of the most salient clinical features in dengue patients. Understanding the parameters released from activated platelets, involving in maintaining the delicate network, can provide a better picture of pathogenic cause of dengue. Ninety four dengue confirmed patients, 24 other febrile patients, and 12 healthy controls were enrolled to study. The parameters including the levels of polyphosphates, bradykinin, thyroxine, nitrite/ nitrate, platelet factor 4 (PF4), and serotonin, from the circulation of dengue patients were quantified by commercial ELISA kits and then compared to that from patients with other febrile illnesses, follow-up samples, and healthy controls. The following results were documented.

Results

1. The levels of polyphosphates were on average $30 \%$ higher in acute dengue samples than healthy controls.

2. The levels of thyroxine, and nitrite/nitrate were significantly higher in acute dengue samples compared to that of other febrile, follow-up and healthy samples, while bradykinin was significantly lower.

3. The levels of PF4 were not different among samples of acute dengue, other febrile illness and follow-up, but were all significantly higher than the healthy controls.

4. The levels of serotonin were significantly higher in acute febrile stage compared to convalescent stage; while significantly lower than healthy subjects. The dynamic network of biochemical programs that coordinate to maintain hemostasis become unbalanced during and following dengue virus infection. Factors released from activated platelets may influence the vascular permeability.

Keywords: Dengue; Thrombocytopenia; Flavivirus; Hemorrhagic fever

\section{Introduction}

Inflammation resulting from immune responses and hemostasis are interrelated pathophysiologic processes; changes in one system can considerably affect the other. They act as a Yin and Yang within the body's intricate circulatory network to maintain a constant normal physiological state, especially under disease conditions. This important set of programs provides humans a defense strategy against microorganisms in their natural surroundings. Minor imbalances in circulatory factors may result in detrimental, and on some occasions, unrecoverable outcomes. The coordination of this sophisticated and hierarchical network of monitors and surveillance systems among the body's other operational programs is very critical to maintain homeostatic and hemostatic conditions at all times. Under microbial attacks or disease conditions, all constituents of these programs within the system are orderly engaged to restore the body to its default status. However, in some situations, one or more programs may deviate from the assigned tasks, resulting in abnormal activation of particular biochemical feedback loops, which likely cause a domino effect leading to minor, moderate, or total failure of the system. This scenario likely occurs during infections with pathogens, since they are equipped with evasion programs that disturb the balance of the hosts' hemostasis and/ or immune response in order to survive in the hostile environment. When imbalances occur, the constitutively operating network programs can work in conjunction with the induced/inhibited cascade chain reactions and either resolve the issue or trigger an unexpected outcome. An example of this type of scenario can be found in dengue virus infections.

Dengue has been associated with human beings for more than 200 years, mainly in tropical and subtropical geographical zones. With its recent expansion, the disease has been recognized as one of the most

${ }^{*}$ Corresponding authors: Jih-Jin Tsai, Tropical Medicine Center, Kaohsiung Medical University Hospital, Kaohsiung, Taiwan, E-mail: jijits@cc.kmu.edu.tw

Guey Chuen Perng, Department of Microbiology and Immunology, College of Medicine, National Cheng Kung University, Tainan, Taiwan, E-mail: gperng@mail.ncku.edu.tw

Received August 02, 2013; Accepted August 27, 2013; Published September 01, 2013

Citation: Tsai JJ, Chen PC, Liu LT, Chang K, Yao JH, et al. (2013) Pathogenic Parameters Derived from Activated Platelets in Dengue Patients. Trop Med Surg 1: 142. doi: 10.4172/2329-9088.1000142

Copyright: (C) 2013 Tsai JJ, et al. This is an open-access article distributed unde the terms of the Creative Commons Attribution License, which permits unrestricted use, distribution, and reproduction in any medium, provided the original author and source are credited. 
important vector-borne human diseases globally [1]. It is estimated that approximately 50 to 100 million of the world's population are at risk of dengue virus infection. Although the majority of infected individuals are asymptomatic, a certain percentage of subjects develop Dengue Fever (DF), Dengue Hemorrhagic Fever (DHF), and DHF with dengue shock syndrome (DSS); DHF/DSS has a high mortality rate and is characterized by plasma leakage and shock due to an increase in vascular permeability [1]. Dynamic clinical presentations make the disease one of the most difficult to diagnose by attending physicians. Currently, no FDA approved vaccine or therapeutic modality is available to prevent, treat, and/or mitigate the progression of the disease. Palliative care is the most common practice to improve patient's clinical conditions.

One of the most salient clinical features in dengue patients is hematological disorder, which may result from thrombocytopenia since it has been associated with disease severity [2,3]. Despite the intensive efforts that have been made for more than 5 decades, the factors and mechanisms contributing to the increase of vascular permeability in dengue patients remains poorly defined. Coagulation is facilitated predominantly by platelets, which upon activation carry and release various biomolecules. Platelet activation may result directly from attack by dengue virus and the formation of immunecomplexes, as well as indirectly from the induction of inflammation [3-6]. Pathophysiological conditions, such as the increase in vascular permeability and imbalances in hemostasis, are constant findings in severe dengue clinical settings [1]. These disturbances may be derived from the dysfunction of activated platelets and low platelet counts. Although several molecules can be secreted from activated platelets and intensive investigations have been performed on many of these that modulate coagulation and hemostasis, some of these parameters are underappreciated. We therefore focused on those biomolecules that are underreported, but perhaps very critical, dynamic players and applied them to the broader picture of the entire regulatory network during dengue virus pathogenesis. These parameters include polyphosphates, bradykinin (vasodilator), nitrate/nitrite, thyroxine, and serotonin in collected sera from dengue patients.

\section{Materials and Methods}

\section{Patient recruitment}

This study was approved by the institutional review board of Kaohsiung medical university hospital (KMUH). Enrolled patients were people older than 15 years old who visited KMUH and were diagnosed with acute dengue virus infection by the laboratory confirmation standards set by Taiwan CDC and according to the 1997 WHO diagnostic guidelines [7]. The diagnosis was based on either of the following laboratory criteria: Dengue virus RNA detection in serum; Dengue virus isolation from serum; Dengue NS1 antigen detection; and/or Dengue virus-specific IgM and IgG antibody detection. $8 \mathrm{ml}$ of blood was drawn from each enrolled subject for this study. From 2009 till now, 94 dengue cases, 24 other febrile illness, and 24 follow-up cases were collected. Blood from 12 healthy volunteers was used as a control in these studies. All blood-drawn patients had dengue fever according to the WHO diagnostic guidelines [7]. All samples were collected with tubes containing protease inhibitors.

\section{Serology and virus assays}

$\operatorname{IgM}$ and $\operatorname{IgG}$ to dengue virus were measured in all specimens by antibody capture Enzyme Immunoassay (EIA) as described previously $[8,9]$. The antibody measurement was employed to confirm the causative agent was dengue virus and was not intended to differentiate between primary and secondary infection. Thus, all the antibodies were measured with one time point. Reverse Transcriptase-Polymerase Chain Reaction (RT-PCR) was used to identify the infecting serotype in specimens as described previously [5].

\section{Blood coagulatory parameters assays}

Detection of polyphosphate: A metachromatic assay with toluidine blue (TBO) was used to quantify polyphosphate. The TBO method is based on decreases in absorbance at $620 \mathrm{~nm}$ by metachromatic reaction of TBO (base) with polyphosphate (acid). Briefly, platelet supernatant was diluted 1:3 in carbonate/bicarbonate buffer $\left(3.03 \mathrm{~g} \mathrm{Na}_{3} \mathrm{CO}_{3}, 6 \mathrm{~g}\right.$ $\mathrm{NaHCO}_{3}, 1 \mathrm{~L} \mathrm{H}_{2} \mathrm{O}, \mathrm{pH}$ 9.6) and $100 \mu \mathrm{l}$ were distributed into a 96well plate. $100 \mu \mathrm{l}$ of TBO assay solution $(0.05 \mathrm{mg} / \mathrm{mL}$ TBO in $0.1 \mathrm{~N}$ acetic acid) was added to each well, incubated for 15 minutes, and the absorbancy at $620 \mathrm{~nm}$ was measured within 30 minutes.

\section{Platelet Factor 4 (PF4) assay}

The PF4 concentration in the serum was quantified with PF4 Human ELISA Kit (Abcam Inc., Cambridge, MA) using the manufacturer's provided protocol. The detection limit for PF4 is approximately at 20 $\mathrm{pg} / \mathrm{ml}$.

\section{Bradykinin assay}

The levels of bradykinin in collected samples were measured with Bradykinin EIA Kit (Phoenix pharmaceuticals, Inc., Burlingame, CA) and performed according to the manufacturer's suggested protocol. The detection limit for bradykinin is at $0.08 \mathrm{ng} / \mathrm{ml}$.

\section{Nitrite/Nitrate assay}

The total concentration of Nitrite/Nitrate in the serum was measured with Nitrate/Nitrate Colorimetric Assay kit (Cayman Chemical Company, Ann Arbor, MI) and was performed according to the manufacturer's suggested protocol. The detection limit for the nitrite/nitrate is at $2.0 \mu \mathrm{M}$.

\section{Thyroxine (T4) assay}

Infection can alter lots of physiological changes including hormone, for example, the levels of thyroxine. Thus, the levels of total T4 in serum were performed with Thyroxine (T4) ELISA Kit (Calbiotech Inc., Spring Valley, CA) and performed according to the manufacturer's suggested protocol. The detection limit for Thyroxine T4 is at $20 \mathrm{ng} / \mathrm{ml}$.

\section{Serotonin assay}

The levels of serotonin in serum were performed with Serotonin Elisa Kit (Abcam, Cambridge, MA) and performed according to the manufacturer's suggested protocol. The detection limit for serotonin is at $0.293 \mathrm{ng} / \mathrm{ml}$.

\section{Statistic analysis}

Statistic analyses were performed with GraphPad Prism V5.04, a GraphPad Software Inc. product. Results were considered statistically significant when $\mathrm{P}$ was $<0.05$.

\section{Results}

\section{Patient enrollment}

Between September 2010 to January 2012, samples were obtained from 94 patients with clinical and laboratory confirmed acute dengue. Twenty four patients were called in for a second blood drawing. Also, 24 patients with other febrile illness and 12 healthy normal subjects 
were recruited for the study. The demographic data of these subjects and the basal line points of the dengue patients are shown in Table 1. Ages ranged from 19 to 74 years, with an average of $44.5 \pm 14.0$ years. The number of males to females was very similar or equal in all groups. More than half of the dengue patients required hospitalization, and the length of the hospitalization ranged from 1 to 10 days, with an average of $5.6 \pm 2.2$ days. No statistical significance was observed, even though female patients appeared to stay hospitalized longer (6.0 \pm 1.9 days) than males ( $4.9 \pm 2.4$ days). Forty six percent (43/94) of the dengue patients had discernible underlying diseases, while 41\% (39/94) had disease-associated conditions. The most dominant underlying diseases were Hepatitis B Virus infection, cardiovascular disease with hypertension $(\mathrm{CVH} / \mathrm{T})$, and diabetes mellitus $(\mathrm{DM})$, while the most dominant associated conditions were hepatitis, diarrhea, vomiting, and nausea (Figure 1). We defined hepatitis by the elevation of Aspartate aminotransferase (AST or GOT) or Alanine aminotransferase (ALT or GPT) 5 times more than the normal range (below $40 \mathrm{IU} / \mathrm{L}$ ). The dengue cases associated with hepatitis had underlying hepatitis B infection (4) and hepatitis $\mathrm{C}$ infection (1). Other minor underlying diseases and associated conditions are listed in supplementary Table 1. Many of these underlying diseases and associated conditions are consistent with previous literature reports [10]. However, if WHO 2009 guideline was applied, only one case fulfilled severe dengue (AST/GOT 339 IU/L and ALT/GPT $1189 \mathrm{IU} / \mathrm{L}$ ). In addition, 27 victims fulfilled dengue cases with warning signs (AST/GOT: $\mathrm{n}=24$; median 43 IU/L (Range 24-293)

\begin{tabular}{|c|c|c|c|c|}
\hline & Acute Dengue & Follow-up & OFI & Healthy Control \\
\hline Number & 94 & 24 & 24 & 12 \\
\hline $\operatorname{Sex}(M: F)$ & $43: 51$ & $12: 12$ & $14: 10$ & $5: 7$ \\
\hline \multirow{2}{*}{$\begin{array}{c}\text { Age } \\
\text { (average } \pm \\
\text { SD) }\end{array}$} & \multirow{2}{*}{$\begin{array}{l}M: 44.7 \pm 15.1 \\
F: 44.6 \pm 13.2\end{array}$} & M: $37.3 \pm 14.2$ & M: $40.0 \pm 16.4$ & M: $31.0 \pm 7.5$ \\
\hline & & $F: 41.1 \pm 11.2$ & $F: 35.4 \pm 13.7$ & $F: 32.4 \pm 9.5$ \\
\hline $\begin{array}{c}\text { Hospitalized } \\
(\%)\end{array}$ & $\begin{array}{l}\text { M: } 24 / 43(55.8) \\
F: 36 / 51(70.6)\end{array}$ & $\mathrm{N} / \mathrm{A}$ & N/A & $\mathrm{N} / \mathrm{A}$ \\
\hline $\begin{array}{l}\text { Length of } \\
\text { hospitaliza- } \\
\text { tion (average } \\
\pm S D \text { ) }\end{array}$ & $\begin{array}{l}M: 4.9 \pm 2.4 \\
F: 6.0 \pm 1.9\end{array}$ & N/A & N/A & $\mathrm{N} / \mathrm{A}$ \\
\hline $\begin{array}{c}\text { Underlying } \\
\text { diseases (\%) }\end{array}$ & $\begin{array}{l}\text { M: } 21 / 43(48.8) \\
F: 22 / 51(43.1)\end{array}$ & N/A & $\mathrm{N} / \mathrm{A}$ & $\mathrm{N} / \mathrm{A}$ \\
\hline $\begin{array}{c}\text { Associated } \\
\text { Conditions } \\
(\%)\end{array}$ & $\begin{array}{l}\text { M: } 22 / 43(51.2) \\
F: 17 / 51(33.3)\end{array}$ & N/A & N/A & N/A \\
\hline
\end{tabular}

Other febrile illnesses (OFI). \pm , Standard Deviation (SD). Not applicable or not acquired (N/A).

Table 1: Demographic profile and basal line of the enrolled patients.
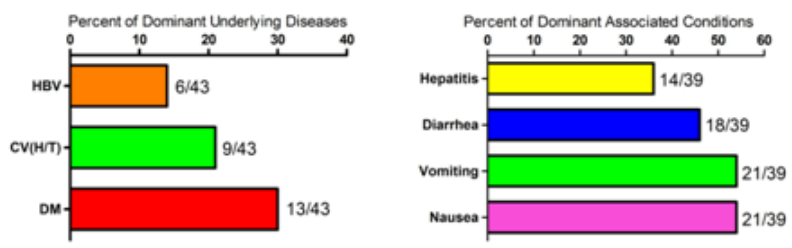

Figure 1: Dominant underlying diseases and associated conditions in enrolled patients.

(A) Dominant underlying diseases. There were 43 patients who presented with underlying diseases upon enrollment. The most common underlying diseases in these subjects were, diabetes mellitus (DM), Cardiovascular disease with hypertension $(\mathrm{CVH} / \mathrm{T})$, and Hepatitis B Virus infection (HBV). (B) Associated conditions. The most common associated conditions in enrolled patients were nausea, vomiting, diarrhea, and hepatitis. and ALT/GPT: $\mathrm{n}=24$; median $45 \mathrm{IU} / \mathrm{L}($ Range 14-188)). There was no subject with shock or clinically detectable plasma leakage in this study.

\section{Immune cells in circulation}

The cellular distributions in the blood are displayed in Table 2. The lowest whole blood counts (WBC) were observed on days 4 to 7 , while the lowest platelet counts were noticed from days 5 to 7 after the onset of fever. Although within normal range, fluctuations of lymphocytes and monocytes were observed during the first week after fever onset. Varying amounts of atypical lymphocytes were seen throughout the first week of the illness. In addition, a consistent rise of hemoglobulin and a moderate increase of hematocrit were noticed at later days of illness.

\section{Viral materials and antibodies in the peripheral blood}

The components related to the dengue virus are summarized in Table 2. Dengue viral RNA genome was readily detectable in early samples acquired near the onset of fever and dropped significantly at the end of the week at the beginning of severe symptoms. Dengue viral antigen, nonstructural protein 1 (NS1) appeared to be much more sensitive than viral RNA detection by RT-PCR at later time points of illness. From the IgM and IgG profiles, most of our dengue patients were in the category of primary infection. Dengue virus serotype 2 accounted for $60 \%$ of the cases, while dengue virus serotype 3 was responsible for the rest.

\section{Releasates from activated platelets}

Activation of platelets in the circulation is one of the salient hallmarks of dengue patients. Numerous releasates can be secreted from the activated platelets. Since the majority of these releasates have been investigated comprehensively $[11,12]$, we focused on the polyphosphates (polyP), a linear polymer of inorganic phosphate stored in the dense granules of human platelets [13]. Considering that hematological disorders are common in dengue patients, it is anticipated that the levels of polyP would increase compared to healthy control. Results revealed that the levels of polyP were on average $30 \%$ higher than healthy control subjects (Figure 2A). This evidence suggests that polyP may contribute to the imbalance of hemostasis under disease conditions.

\section{Levels of bradykinin and thyroxine}

One function of polyP is to directly bind and aTTre significantly higher than healthy subjects and other febrile illness (Figure 3 ). This result is consistent with reports demonstrating that endocrine circuits can mediate inhibition of bradykinin-induced plasma extravasation and that T4 may enhance venous thrombosis by shifting the hemostatic balance towards a more hypercoagulable and hypofribrinilytic state $[17,18]$. This data also suggests that a much more intricate network of regulatory programs is involved in the maintenance of hemostasis during viral infections.

\section{Nitric oxide levels in sera of dengue patients}

Nitric oxide (NO) is a diffusible, short-lived, diatomic radical ubiquitously produced by mammalian cells including activated platelets [19]. NO regulates a wide range of cellular processes in the body, such as dilating blood vessels, aggregating platelets, fighting infections and tumors, mediating inflammation and macrophage cytotoxic activity, and transmitting signals between nerve cells [20,21]. Many of these NO regulated signaling cascades can become perturbed during disease. 
Citation: Tsai JJ, Chen PC, Liu LT, Chang K, Yao JH, et al. (2013) Pathogenic Parameters Derived from Activated Platelets in Dengue Patients. Trop Med Surg 1: 142. doi: 10.4172/2329-9088.1000142

Page 4 of 7

\begin{tabular}{|c|c|c|c|c|c|c|c|c|}
\hline DOI & 1 & 2 & 3 & 4 & 5 & 6 & 7 & 8 \\
\hline \# of cases & 11 & 12 & 12 & 22 & 10 & 14 & 8 & 5 \\
\hline WBC (per $\mu \mathrm{l})$ & $6.7 \pm 2.4$ & $4.9 \pm 2.2$ & $4.4 \pm 1.4$ & $3.2 \pm 1.3$ & $3.6 \pm 2.4$ & $3.1 \pm 1.3$ & $3.2 \pm 1.8$ & $4.6 \pm 2.5$ \\
\hline $\begin{array}{l}\text { Platelets } \\
\left(\mathrm{X} 10^{3} / \mu \mathrm{l}\right)\end{array}$ & $183 \pm 30$ & $142 \pm 61$ & $143 \pm 39$ & $117 \pm 55$ & $93 \pm 63$ & $101 \pm 38$ & $90 \pm 45$ & $140 \pm 59$ \\
\hline Lymphocyte s (\%) & $12 \pm 8$ & $14 \pm 11$ & $11 \pm 7$ & $16 \pm 11$ & $19 \pm 15$ & $22 \pm 13$ & $12 \pm 13$ & $36 \pm 9$ \\
\hline Monocytes (\%) & $9 \pm 4$ & $11 \pm 6$ & $12 \pm 6$ & $12 \pm 5$ & $9 \pm 3$ & $12 \pm 6$ & $14 \pm 5$ & $13 \pm 7$ \\
\hline Atypical Lymphocyte s (\%) & $0.6 \pm 1.8$ & $2.5 \pm 8.1$ & $0.2 \pm 0.6$ & $0.4 \pm 1.1$ & $0.0 \pm 0.0$ & $0.6 \pm 1.2$ & $0.8 \pm 2.3$ & $3.6 \pm 2.5$ \\
\hline $\mathrm{Hb}(\mathrm{g} / \mathrm{dl})$ & $13.1 \pm 1.5$ & $13.7 \pm 1.0$ & $13.4 \pm 1.1$ & $14.1 \pm 1.3$ & $14.9 \pm 1.2$ & $14.6 \pm 1.7$ & $14.0 \pm 1.6$ & $15 \pm 0.7$ \\
\hline Hct $(\%)$ & $37.8 \pm 3.7$ & $39.8 \pm 2.8$ & $29.3 \pm 3.4$ & $42.0 \pm 3.1$ & $43.2 \pm 3.3$ & $43.0 \pm 4.5$ & $40.8 \pm 4.1$ & $42.4 \pm 1.5$ \\
\hline DV RT-PCR+(\%) & $11 / 11(100)$ & $11 / 12(92)$ & $9 / 12(75)$ & $16 / 22(73)$ & $6 / 10(60)$ & $7 / 14(50)$ & $2 / 8(25)$ & $1 / 5(20)$ \\
\hline DV NS1+(\%) & $11 / 11(100)$ & $11 / 12(92)$ & $10 / 12(83)$ & $18 / 22(82)$ & $7 / 10(70)$ & $9 / 14(64)$ & $4 / 8(50)$ & $2 / 5(40)$ \\
\hline DV $\lg M+(\%)$ & $1 / 11(9)$ & $1 / 12(8)$ & $1 / 12(8)$ & $6 / 22(27)$ & $6 / 10(60)$ & $9 / 14(64)$ & $6 / 8(75)$ & $4 / 5(80)$ \\
\hline DV $\lg G+(\%)$ & $0 / 11(0)$ & $0 / 12(0)$ & $1 / 12(8)$ & $2 / 22(9)$ & $2 / 10(20)$ & 4/14 (29) & $3 / 8(36)$ & $2 / 5(40)$ \\
\hline
\end{tabular}

Day of Infection (DOI). Whole blood count (WBC). Hemoglobin (Hb). Hematocrit (Hct). Dengue virus (DV). \pm , standard deviation

Table 2: Blood parameters in dengue confirmed patients.
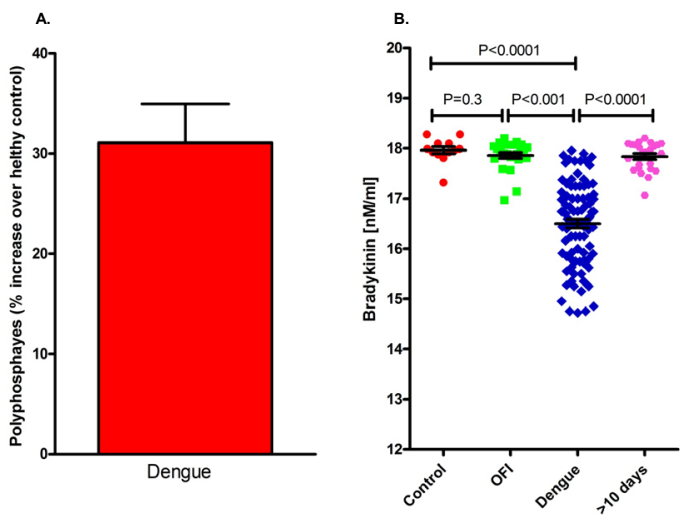

Figure 2: Higher levels of polyphosphates and lower amounts of bradykinin in dengue patients. (A) Levels of polyphosphates. Polyphosphates in patient and healthy plasma were measured as described in the Materials and Methods. An average of $30 \%$ higher polyphosphate levels were observed in dengue patients compared to healthy subjects. (B) Levels of bradykinin. The levels of bradykinin were surprisingly and significantly lower than healthy controls, other febrile illness (OFI), and samples from dengue subjects collected more than 10 days after onset of fever.

Due to the extremely short physiological half-life of this gaseous free radical, alternative strategies were developed for the detection of NO biochemical reaction products. In plasma or other physiological fluids or buffers NO is oxidized almost completely to nitrite and nitrate, a state in which it remains stable for several hours [22-24].

The levels of nitrite/nitrate in the sera of acute dengue patients were significantly higher than that of healthy controls, other febrile illness, and the follow-up samples (Figure 4). The levels of NO in mediating its physiologic or protective effects are crucial. Free radical activity of NO can cause cellular damage through nitrosative stress [25]. High concentrations of NO may suppress proliferation and/or induce apoptosis of a wide range of cell types. NO prevents $\mathrm{P}$-selectin-protein expression [26], while inhibition of NO leads to P-selectin-dependent platelet adhesion [26,27] and increased platelet aggregability [28]. In other words, the quantification of NO metabolites in biological samples provides valuable information with regards to in vivo NO production, bioavailability, and metabolism and may be useful as an indicator of disease severity.

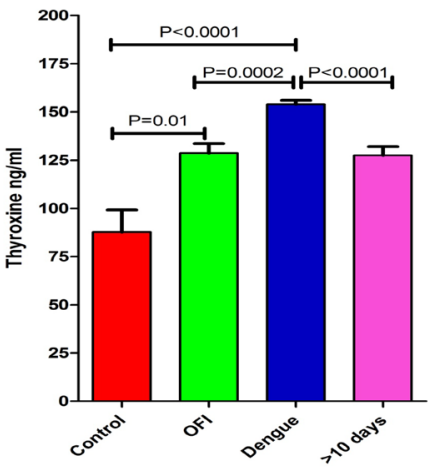

Figure 3: Higher levels of thyroxine in dengue patients. The levels of thyroxine in sera of healthy control, other febrile illness (OFI), dengue, and samples collected more than 10 days after the onset of fever. The amounts of thyroxine in dengue patients were significantly higher that healthy, OFI, and samples collected more than 10 days. In addition, the thyroxine levels in plasma were significantly increased in OFI and samples collected more than 10 days after onset of fever compared to healthy samples. Healthy control range: 50-110 $\mathrm{ng} / \mathrm{ml}$.

\section{Platelet factor 4 in dengue patients}

The platelet factor 4 (PF4), also known as CXCL4, is a chemokine secreted from activated platelets. PF4 has been implicated in inflammation caused by a number of pathogens. The levels of PF4 were evaluated in sera of dengue patients. Results indicated that the amounts of PF4 were not different in acute serum samples compared to other febrile illnesses and convalescent samples, although they were significantly higher than healthy controls (Figure 5). These results also suggest that activated platelets may persist for a long period of time in dengue patients, even though it is also possible that this platelet hyperactivation may indicate an undiagnosed secondary infection.

\section{Serotonin in serum of dengue patients}

Platelets serve as the major reservoir of serotonin in the bloodstream. When activated, platelets release serotonin into the bloodstream where it acts as a powerful vasoconstrictor. The levels of serotonin in collected samples were shown in Table 3. In acute sera, less than 4 days of fever, the levels of serotonin, on average was significantly lower than that of healthy subjects, even though slightly higher than 


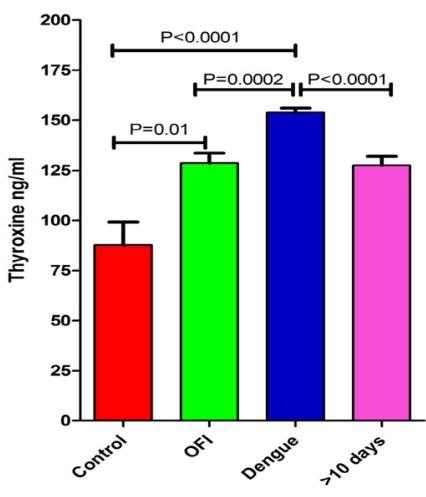

Figure 4: The levels of nitrite/nitrate were significantly higher in dengue patients. The concentrations of nitrite/nitrate in sera were quantified as described in the Materials and Methods. The levels of nitrite/nitrate in serum of dengue patients were significantly higher than healthy, OFI, and samples collected more than 10 days after the onset of fever. No differences were observed in samples among healthy, OFI, and more than 10 days after the onset of fever.

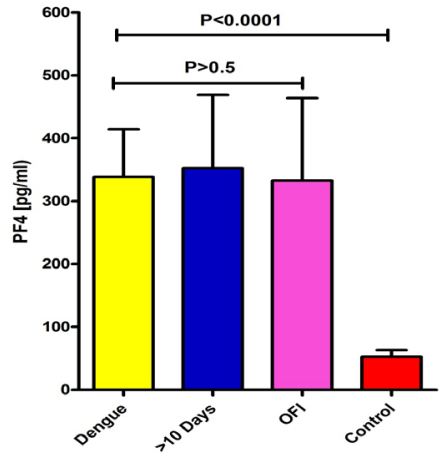

Figure 5: Levels of platelet factor 4 (PF4) in dengue patients. The amounts of PF4 in sera were measured as described in the Materials and Methods. Compared to healthy control, the levels of PF4 were significantly higher in collected samples among all patient categories. But no differences were seen among these samples from ill patients.

\begin{tabular}{|l|l|l|}
\hline Plasma Samples & Serotonin $[\mathrm{ng} / \mathrm{ml}]$ & $\mathbf{P}$ value \\
\hline $\mathrm{DOF}<4$ & $146.7 \pm 45.41$ & $\begin{array}{l}\text { Vs. DOF } \geq 4, \mathrm{p}<0.0001, \mathrm{vs} \text {. healthy, } \\
\mathrm{p}=0.0022, \mathrm{Vs} . \mathrm{OFI}, \mathrm{P}=0.124\end{array}$ \\
\hline $\mathrm{DOF} \geq 4$ & $61.30 \pm 18.43$ & Vs. OFI, $\mathrm{P}=0.0332, \mathrm{Vs}$. \\
\hline Healthy, $\mathrm{P}=0.0008$ & & \\
\hline OFI & $105.9 \pm 49.53$ & Vs. Healthy, $\mathrm{P}=0.0025$ \\
\hline Healthy Subjects & $323.9 \pm 15.62$ & \\
\hline
\end{tabular}

DOF=Days of fever; OFI=other febrile illness; $\pm=$ =Std. derivation.

Table 3: Levels of serotonin in sera of dengue patients.

that of OFI. Noticeably, the levels of serotonin at the fever late $>4$ days were significantly lower than healthy control as well as early acute dengue stage and OFI.

\section{Discussion}

The Yin-Yang harmony of the body's physiology has been philosophically known about for more than a thousand years.
This concept applies perfectly to the process of pathophysiological maintenance, especially to the bidirectional relationship between inflammation and hemostasis [29]. Inflammation caused by many conditions, including infections, leads to activation of biochemical pathways in the hemostatic system that in turn back talks, influencing the inflammatory activity. An inflammation-hemostasis cycle is a regulatory process in which each activated cascade promotes the two systems, functioning in a positive feedback loop. The extensive crosstalk between the immune and hemostatic systems occurs at a level for all components within the hemostatic system, including the platelets, vascular endothelial cells, and plasma coagulation cascade factors.

Circulating platelets are the second most numerous peripheral blood cells in humans. Upon disease development, their counts can drop from $200-300 \times 10^{6}$ to under 10,000 per $\mathrm{ml}$ of blood. Platelets are an abundant source of soluble factors including various vasoactive components, biomediators, chemokines, and inflammatory cytokines. The amounts of biomediators released from the activated platelets often are physiologically overwhelming, and yet its impact on the pathophysiology of disease development and its activity within the capillary micro-environment has not been the center of the attention. Aberrant platelet activation and clearance is one of many proposed mechanisms leading to thrombocytopenia during DHF [4,30,31].

Platelet-derived polyphosphate has recently been described as a new class of mediators playing a role in platelet-driven inflammation. Polyphosphate is an inorganic polymer of 60-100 phosphate residues linked by phosphoanhydride bonds. It is abundant in nature and has been studied extensively in prokaryotes and lower eukaryotes where it functions in metabolism, stress management, and in structural stability. Despite its widespread presence, not much is known about the in vivo role of polyphosphate in mammalian cells. Synthetic polyP has been demonstrated to be a potent modulator of plasma clotting that affects the induction of the intrinsic pathway, the fibrinolytic system, the activation of factor $\mathrm{V}$, and the fibrin structure $[32,33]$. Moreover, it is reported that the dense granules of platelets contain 10-20 times more polyphosphate than other human tissues [34-36]. Recently, Muller et al. demonstrated that platelet-derived polyphosphate led to fibrin formation and vascular leakage in mice [14].

The levels of polyphosphates in sera of acute dengue patients were on average $30 \%$ higher than that of healthy controls. The evidence suggests that high levels of polyphosphates were likely released from activated platelets in dengue patients. Polyphosphates can directly bind to and activate the plasma protease factor XII, which in turn triggers the release of the inflammatory mediator bradykinin by plasma kallikrein-mediated kininogen processing. To our surprised, the levels of bradykinin in sera of acute dengue were significantly lower than healthy controls and other febrile illness. The result suggests that an alternative program may be involved in the initiation of the intrinisic pathway and orchestration of coagulation. One such program is the link between the hemostatic, inflammatory and endocrine systems.

Endocrine changes have been widely studied in critical illness such as septic or cardiogenic shock, trauma and extensive burns, but they have rarely been studied in dengue. One report suggests that thyroid axis is influenced by the dengue illness similar to changes in euthyroid sick syndrome [15]. We observed that the levels of thyroxine were significantly increased in samples of acute dengue patients. Perhaps, the endocrine regulatory loop is a program that can restore hemostasis under disease conditions. Interestingly, several reports demonstrated that an intricate relationship exists between platelet function and thyroxine since treatment of chronic thrombocytopenia patients with 
this hormone can rescue the platelet count [16] and increase risk of developing venous thrombosis when a large amount of free thyroxine is administrated to healthy volunteers [18,37]; also the diminution of the inflammatory response is observed after thyroidectomy [38]. The evidence suggests that the endocrine system may play a critical role in the restoration and recovery process of hemostasis under disease conditions. The underlying mechanisms by which thyroid hormones may affect coagulation remain to be further explored. Questions still remain, such as whether the increased levels of thyroxine, which can regulate platelet function, in acute dengue patients can compensate or account for the lower levels of bradykinin and/or abnormal hemostasis.

Bradykinin is one of the most potent vasodilators since it is capable of inducing endothelium-derived vasodilatory mediator, NO [39]. Bradykinin plays a major role in dilation of the peripheral and coronary vessels, and exerts anti-thrombogenesis, anti-proliferative and antifibrogenic effects [40-43]. Compelling evidence linking bradykinin to pathophysiological processes that induce tissue damage and inflammation, hyperaemia, leakage of plasma proteins, bone resorption induced by inflammation and pain [44-46] has been established. However, there is only one other study looking at the plasma kinin system in dengue [47], hence the role of bradykinin in dengue patients is inconclusive. Both this report and the one by Edelman agree that bradykinin levels are not elevated. However there may be a need for samples to be collected and evaluated fresh; the fragile bradykinin products may not have been preserved sufficiently enough to avoid its breakdown and accurately determine its concentrations.

$\mathrm{NO}$ is a pleiotropic biomodulator in several systems including homeostasis. Nitrite has been investigated as a vasodilator in mammals for over 125 years and is a known by-product of organic nitrate metabolism. Nitrite could be a stable endocrine carrier and transducer of NO-like bioactivity within the circulation [48]. But the amount of the NO in circulation is very critical since it can lead to beneficial or harmful effects. Dose response in human volunteer studies revealed that a significant level of vasodilation in the circulation of the forearm was already present at a concentration as low as $300 \mathrm{nM}$ [49] and that a significant decrease in blood pressure occurred after nitrate ingestion, associated with an increase in plasma nitrate levels from 140-220 nM [50]. NO can be released by numerous cells including activated platelets and neutrophils. The functions of NO involve signaling and regulation of a wide variety of complex cellular processes, such as platelet function, vasodilation, and immunity among others [51]. Although a strong correlation has been noticed between NO synthesis impairment in platelets and vascular diseases, the actual instigator in inducing the increase of vascular permeability in dengue patients remain unknown.

Serotonin (5-hydroxytryptamine, 5-HT) is a neurotransmitter in the brain that has an enormous influence over many brain functions and its synthesis begins with dietary L-tryptophan. The fate of tryptophan is in the comparative activities of enzymes indoleaminedioxygenase (IDO)/tryptophan dioxygenase to produce kyurenine and tryptophan hydroxylase to produce $5 \mathrm{HT}$. An estimated $5-10 \%$ of tryptophan is shuttled through the TPH/5HT pathway. Dengue patients have been shown to have increased IDO, reduced L-tryptophan, and increased L-kynurenine during the febrile pro inflammatory phase. Importantly, the increased activity of IDO in serum from acutely infected dengue patients has been linked to gamma interferon antiviral function [52]. So the metabolism is biased toward the IDO pathway and away from 5HT, deviating the classical role of serotonin to be an acute vasoconstrictor. A basic idea is that early infection generates compensatory serotonin responses, for example, vasodilation to accomplish heat loss; and site-specific release for local inflammation; but infection of platelets destabilizes serotonin system, with net result poor serotonin uptake by platelets, and pathologic increases in circulating serotonin. Peripheral serotonin actions such as prolonged hypotension, are not balanced because of simultaneous increases in central serotonin activity (driven by fever and soluble inflammatory factors). This model would predict elevated circulating peripheral serotonin. But actually, you could have it either way. If circulating serotonin were low, well, that is the usual idea: that shock is blood loss, platelet loss, and low serotonin. Perhaps, this may be one of the transient critical parameters released from activated platelets, which can have a central role in vascular permeability.

Furthermore, the functions of serotonin are numerous and appear to involve control of appetite, sleep, memory and learning, temperature regulation, mood, behavior (including sexual and hallucinogenic behavior), cardiovascular function, muscle contraction, endocrine regulation, and depression [53,54]. Interestingly, the prevalence of anxiety and depression symptoms in patients with dengue has been reported [55].

The intricacy of the regulation and maintenance of the physiological balance has to function accordingly in order to overcome the pathophysiological situations and restore hemostasis under infection. Systemic infections in general may influence hemostasis, leading to multiple outcomes including thrombohemorrhagic complications and Disseminated Intravascular Coagulation (DIC) in the most severe dengue patients. Generally speaking, the coagulation abnormalities commonly associated with dengue patients are thrombocytopenia and an increased fibrinolysis, suggesting that additional regulatory parameters already known to play a role in hemostasis, such as the endocrine, are likely involved in dengue disease development. In order to have a much more comprehensive understanding of dengue virus pathogenesis, this intertwined relationship needs to be further explored in the setting of dengue virus infection in patients.

\section{Acknowledgements}

We would like to thank the clinical staff at the Tropical Medicine Center and Division of Infectious Diseases of Kaohsiung Medical University Hospital. Research was supported by a startup grant from the National Science Council (NSC99-2321-B006-008) (GCP) with the Center of Infectious Disease and Signaling Research, NCKU, Taiwan, and Grants from Taiwan National Science Council (NSC 99-2745-B-037-002) (JJT)

\section{References}

1. Alam R, Siddiqui FM, Rahman S, Haque AK, Sarker CB, et al. (2004) Management of dengue by the WHO guided national guidelines. Mymensingh Med J 13: 43-47

2. Krishnamurti C, Kalayanarooj S, Cutting MA, Peat RA, Rothwell SW, et al (2001) Mechanisms of hemorrhage in dengue without circulatory collapse. Am J Trop Med Hyg 65: 840-847.

3. Saito M, Oishi K, Inoue S, Dimaano EM, Alera MT, et al. (2004) Association of increased platelet-associated immunoglobulins with thrombocytopenia and the severity of disease in secondary dengue virus infections. Clin Exp Immunol 138: 299-303.

4. Alonzo MT, Lacuesta TL, Dimaano EM, Kurosu T, Suarez LA, et al. (2012) Platelet apoptosis and apoptotic platelet clearance by macrophages in secondary dengue virus infections. J Infect Dis 205: 1321-1329.

5. Noisakran S, Gibbons RV, Songprakhon P, Jairungsri A, Ajariyakhajorn C, et al. (2009) Detection of dengue virus in platelets isolated from dengue patients. Southeast Asian J Trop Med Public Health 40: 253-262.

6. Mitrakul C, Poshyachinda M, Futrakul P, Sangkawibha N, Ahandrik S (1977) Hemostatic and platelet kinetic studies in dengue hemorrhagic fever. Am J Trop Med Hyg 26: 975-984.

7. WHO. Dengue Haemorrhagic fever: diagnosis, treatment, prevention and control. (2ndedn). Geneva: World Health Organization; 1997.

8. Vaughn DW, Green S, Kalayanarooj S, Innis BL, Nimmannitya S, et al. (1997) 
Citation: Tsai JJ, Chen PC, Liu LT, Chang K, Yao JH, et al. (2013) Pathogenic Parameters Derived from Activated Platelets in Dengue Patients. Trop Med Surg 1: 142. doi: 10.4172/2329-9088.1000142

Page 7 of 7

Dengue in the early febrile phase: viremia and antibody responses. $J$ Infect Dis 176: $322-330$

9. Innis BL, Nisalak A, Nimmannitya S, Kusalerdchariya S, Chongswasdi V, et al. (1989) An enzyme-linked immunosorbent assay to characterize dengue infections where dengue and Japanese encephalitis co-circulate. Am J Trop Med Hyg 40: 418-427.

10. Thomas L, Verlaeten O, Cabié A, Kaidomar S, Moravie V, et al. (2008) Influence of the dengue serotype, previous dengue infection, and plasma viral load on clinical presentation and outcome during a dengue-2 and dengue-4 coepidemic. Am J Trop Med Hyg 78: 990-998.

11. Srichaikul T, Nimmannitya S (2000) Haematology in dengue and dengue haemorrhagic fever. Baillieres Best Pract Res Clin Haematol 13: 261-276.

12. Halstead SB (1982) Dengue: hematologic aspects. Semin Hematol 19: 116-131.

13. Ruiz FA, Lea CR, Oldfield E, Docampo R (2004) Human platelet dense granules contain polyphosphate and are similar to acidocalcisomes of bacteria and unicellular eukaryotes. J Biol Chem 279: 44250-44257.

14. Müller F, Mutch NJ, Schenk WA, Smith SA, Esterl L, et al. (2009) Platele polyphosphates are proinflammatory and procoagulant mediators in vivo. Cell 139: 1143-1156.

15. Wacharasindhu S, Bunjobpudsa Y, Tongmeesee S, Aroonparkmongkol S, Sahakitrungrueng T, et al. (2009) Endocrine changes in children with dengue virus infection. Asian Biomedicine 3: 557-61.

16. Bowles KM, Turner GE, Wimperis JZ (2004) Resolution of chronic severe refractory thrombocytopenia after treatment of hypothyroidism. J Clin Pathol 57: 995-996.

17. Miao FJ, Jänig W, Green PG, Levine JD (1996) Inhibition of bradykinin-induced synovial plasma extravasation produced by intrathecal nicotine is mediated by the hypothalamopituitary adrenal axis. J Neurophysiol 76: 2813-2821.

18. van Zaane B, Squizzato A, Huijgen R, van Zanten AP, Fliers E, et al. (2010) Increasing levels of free thyroxine as a risk factor for a first venous thrombosis: a case-control study. Blood 115: 4344-4349.

19. Gkaliagkousi E, Ritter J, Ferro A (2007) Platelet-derived nitric oxide signaling and regulation. Circ Res 101: 654-662.

20. Bryan NS (2006) Nitrite in nitric oxide biology: cause or consequence? A systems-based review. Free Radic Biol Med 41: 691-701.

21. Bryan NS, Fernandez BO, Bauer SM, Garcia-Saura MF, Milsom AB, et al. (2005) Nitrite is a signaling molecule and regulator of gene expression in mammalian tissues. Nat Chem Biol 1: 290-297.

22. Yoshida K, Kasama K, Kitabatake M, Imai M (1983) Biotransformation of nitric oxide, nitrite and nitrate. Int Arch Occup Environ Health 52: 103-115.

23. Kelm M (1999) Nitric oxide metabolism and breakdown. Biochim Biophys Acta 1411: 273-289

24. Tannenbaum SR (1979) Nitrate and nitrite: origin in humans. Science 205: $1332,1334-1337$.

25. D'Atri LP, Malaver E, Romaniuk MA, Pozner RG, Negrotto S, et al. (2009) Nitric oxide: news from stem cells to platelets. Curr Med Chem 16: 417-429.

26. Armstead VE, Minchenko AG, Schuhl RA, Hayward R, Nossuli TO, et al. (1997) Regulation of P-selectin expression in human endothelial cells by nitric oxide. Am J Physiol 273: H740-746.

27. Minamino T, Kitakaze M, Sanada S, Asanuama H, Kurotobi T, et al. (1998) Increased expression of P-selectin on platelets is a risk factor for silent cerebral infarction in patients with atrial fibrillation: role of nitric oxide. Circulation 98: $1721-1727$.

28. Takajo $\mathrm{Y}$, Ikeda H, Haramaki N, Murohara T, Imaizumi T (2001) Augmented oxidative stress of platelets in chronic smokers. Mechanisms of impaired platelet-derived nitric oxide bioactivity and augmented platelet aggregability. $\mathrm{J}$ Am Coll Cardiol 38: 1320-1327.

29. Levi M, Keller TT, van Gorp E, ten Cate H (2003) Infection and inflammation and the coagulation system. Cardiovasc Res 60: 26-39.

30. Honda S, Saito M, Dimaano EM, Morales PA, Alonzo MT, et al. (2009) Increased phagocytosis of platelets from patients with secondary dengue virus infection by human macrophages. Am J Trop Med Hyg 80: 841-845.
31. Tsai JJ, Liu LT, Chang K, Wang SH, Hsiao HM, et al. (2012) The importance of hematopoietic progenitor cells in dengue. Ther Adv Hematol 3: 59-71.

32. Smith SA, Morrissey JH (2008) Polyphosphate enhances fibrin clot structure. Blood 112: 2810-2816.

33. Smith SA, Mutch NJ, Baskar D, Rohloff P, Docampo R, et al. (2006) Polyphosphate modulates blood coagulation and fibrinolysis. Proc Natl Acad Sci U S A 103: 903-908.

34. Hernandez-Ruiz L, González-García I, Castro C, Brieva JA, Ruiz FA (2006) Inorganic polyphosphate and specific induction of apoptosis in human plasma cells. Haematologica 91: 1180-1186.

35. Kornberg A, Rao NN, Ault-Riché D (1999) Inorganic polyphosphate: a molecule of many functions. Annu Rev Biochem 68: 89-125.

36. Zakharian E, Thyagarajan B, French RJ, Pavlov E, Rohacs T (2009) Inorganic polyphosphate modulates TRPM8 channels. PLoS One 4: e5404.

37. Stuijver DJ, van Zaane B, Squizzato A, Meijers JC, Otten HM (2010) The effects of an extremely high dose of levothyroxine on coagulation and fibrinolysis. $J$ Thromb Haemost 8: 1427-1428.

38. Bouhnik J, Savoie F, Baussant T, Michaud A, Alhenc-Gelas F, et al. (1988) Effect of thyroidectomy on rat T-kininogen. Am J Physiol 255: E411-415.

39. Busse R, Fleming I (2003) Regulation of endothelium-derived vasoactive autacoid production by hemodynamic forces. Trends Pharmacol Sci 24: 24-29.

40. Bhoola KD, Figueroa CD, Worthy K (1992) Bioregulation of kinins: kallikreins, kininogens, and kininases. Pharmacological reviews 44: 1-80.

41. Groves P, Kurz S, Just H, Drexler H (1995) Role of endogenous bradykinin in human coronary vasomotor control. Circulation 92: 3424-3430.

42. Marceau F, Regoli D (2004) Bradykinin receptor ligands: therapeutic perspectives. Nat Rev Drug Discov 3: 845-852.

43. Duchene J, Schanstra JP, Pecher C, Pizard A, Susini C, et al. (2002) A novel protein-protein interaction between a $\mathrm{G}$ protein-coupled receptor and the phosphatase SHP-2 is involved in bradykinin-induced inhibition of cell proliferation. J Biol Chem 277: 40375-40383.

44. Félétou M, Bonnardel E, Canet E (1996) Bradykinin and changes in microvascular permeability in the hamster cheek pouch: role of nitric oxide. $\mathrm{Br}$ J Pharmacol 118: 1371-1376.

45. Cruwys SC, Garrett NE, Perkins MN, Blake DR, Kidd BL (1994) The role of bradykinin B1 receptors in the maintenance of intra-articular plasma extravasation in chronic antigen-induced arthritis. Br J Pharmacol 113: 940-944.

46. Couture R, Harrisson M, Vianna RM, Cloutier F (2001) Kinin receptors in pain and inflammation. Eur J Pharmacol 429: 161-176.

47. Edelman R, Nimmannitya S, Colman RW, Talamo RC, Top FH Jr (1975) Evaluation of the plasma kinin system in dengue hemorrhagic fever. J Lab Clin Med 86: 410-421.

48. Schechter AN, Gladwin MT (2003) Hemoglobin and the paracrine and endocrine functions of nitric oxide. N Engl J Med 348: 1483-1485.

49. Dejam A, Hunter CJ, Gladwin MT (2007) Effects of dietary nitrate on blood pressure. N Engl J Med 356: 1590.

50. Larsen FJ, Ekblom B, Sahlin K, Lundberg JO, Weitzberg E (2006) Effects of dietary nitrate on blood pressure in healthy volunteers. N Engl J Med 355: 2792-2793.

51. Moncada S, Palmer RM, Higgs EA (1991) Nitric oxide: physiology pathophysiology, and pharmacology. Pharmacol Rev 43: 109-142.

52. Becerra A, Warke RV, Xhaja K, Evans B, Evans J, et al. (2009) Increased activity of indoleamine 2,3-dioxygenase in serum from acutely infected dengue patients linked to gamma interferon antiviral function. J Gen Virol 90: 810-817.

53. Watts SW, Morrison SF, Davis RP, Barman SM (2012) Serotonin and blood pressure regulation. Pharmacol Rev 64: 359-388.

54. Lowry CA, Lightman SL, Nutt DJ (2009) That warm fuzzy feeling: brain serotonergic neurons and the regulation of emotion. J Psychopharmacol 23 392-400.

55. Hashmi AM, Butt Z, Idrees Z, Niazi M, Yousaf Z, et al. (2012) Anxiety and depression symptoms in patients with dengue fever and their correlation with symptom severity. Int J Psychiatry Med 44: 199-210. 